\title{
Effect of Modified HIF-1 $\alpha$ Linked to Carbonic Anhydrase IX Inhibitor and Glycosylated Cisplatin on Solid Tumors: Short Review
}

\author{
Waleed 0. Atta1 ${ }^{*}$, Ahmed Z. Abdel Azeiz ${ }^{2}$ \\ ${ }^{1}$ Faculty of Medicine, Assiut University, Sohag, Egypt \\ ${ }^{2}$ College of Biotechnology, Misr University for Science and Technology (MUST), Giza, Egypt \\ Email: *dangersurgery@gmail.com
}

How to cite this paper: Atta, W.O. and Azeiz, A.Z.A. (2021) Effect of Modified HIF-1 $\alpha$ Linked to Carbonic Anhydrase IX Inhibitor and Glycosylated Cisplatin on Solid Tumors: Short Review. Journal of Biosciences and Medicines, 9, 59-72. https://doi.org/10.4236/jbm.2021.98006

Received: July 16, 2021

Accepted: August 13, 2021

Published: August 16, 2021

Copyright () 2021 by author(s) and Scientific Research Publishing Inc. This work is licensed under the Creative Commons Attribution International License (CC BY 4.0).

http://creativecommons.org/licenses/by/4.0/

(c) (i) Open Access

\begin{abstract}
Many cancer cells in solid tumors are hypoxic or pseudohypoxic and create acidic environment for malignancy progression. Under low oxygen conditions (hypoxia), hypoxia-inducible factors (HIFs) play pathological roles in cancer cell survival and spreading. HIF regulates several genes such as genes of glucose transporters that enhance anaerobic glycolysis, angiogenesis, erythropoiesis and carbonic anhydrase IX (CA-IX). CA-IX is a cell-surface glycoprotein that catalyzes the hydration of $\mathrm{CO}_{2}$ to protons and bicarbonate ions (respiratory acidification). This process is involved in adaptation to acidosis and implicated in cancer progression. Therefore, CA-IX inhibitors (such as sulfonamide-based compounds) showed hoping results in reduction malignancy progression. The article aims to reversal the malignant hypoxic environment in solid tumors to create a condition of weakness within the cancer for further focused cisplatin potency. This article suggests the use of modified synthesized HIF as a drug delivery molecule for both carbonic anhydrase IX inhibitor and glycosylated cisplatin that damages the DNA of malignant cell. HIF molecule has high affinity to bind with CA IX-expressing malignant cells, which is followed by cell entrance via endocytosis. Once the HIF-CisplatinCA-inhibitor complex enters the cell, the carbonic anhydrase inhibitor will improve the cellular $\mathrm{pH}$ that makes the environment unsuitable for HIF $1 \alpha$ function and it may be ubiquitinated. So, the raise in target genes transcription will be arrested. On the other hand, once the synthetized HIF is degraded, the cisplatin molecules will be released inside the malignant cell and start to damage its DNA. This approach may be a good solution for many solid tumors.
\end{abstract}

\section{Keywords}

Hypoxia, Carbonic Anhydrase, Cancer, Cisplatin, Nitric Oxide Donor, 
Glycosylation

\section{Introduction}

\subsection{HIF-1 $\alpha$ Activity Differences in Normoxic and Hypoxic Conditions}

The characteristic features of many tumor cells are that they are hypoxic and acidic compared with its normal cells of the same type. When the oxygen is decreased, hypoxia-inducible factors (HIFs) play physiological and pathological roles in response to decreased oxygen levels (hypoxia). HIFs are dimeric molecules that act as transcriptional factors and degraded in the presence of oxygen. HIF- $1 \alpha$ synthesis occurs in the cytosol and it is degraded by the $26 \mathrm{~s}$ proteasome ubiquitination system in normoxic environment [1].

During hypoxia, HIF- $1 \alpha$ structure is kept intact and binds with HIF-1 $\beta$ (also known as ARNT, aryl-hydrocarbon-receptor nuclear translocator) [2] besides specific coactivators such as $\mathrm{CBP} / \mathrm{p} 300$ that bind with HIF- $1 \alpha$ for activation of HIF translocation and transcription [3]. Then HIF $\alpha$ is translocated to the nucleus, especially to conserved sequences (RCGTG) in the promoter regions of HIF-regulated genes (Hypoxia response elements (HRE) [4]. Hypoxia response elements are the transcriptional targets of $\operatorname{HIF} \alpha$, that are essential for metabolic cellular consequences in the hypoxic condition [5], which preserve the cellular viability such as carbonic anhydrase-IX (CA-IX) that controls intracellular and extracellular $\mathrm{pH}$ for the purpose of malignancy spread, dissemination and growth [2], glucose transporter-1 (GLUT-1), which is a transmembranous glucose transporter [3]. GLUT-3, hexokinase 2, lactate dehydrogenase [6] and vascular endothelial growth factor (VEGF) that has important role in endothelial cell proliferation to form new capillaries and tumor blood vessels in response to hypoxia. The final aim of HIF $\alpha$ is to give the malignant cells the ability for anaerobic glycolysis and angiogenesis, also it helps the malignant cells to be adapted and alive under stressful hypoxic conditions [5] (Figure 1).

\subsection{Regulation of HIF Function}

The HIF function is regulated by some biological reactions such as: 1) S-nitrosylation of cysteine 800: This is the key factor for gene transcription control [7], 2) HIF hydroxylation: The hydroxylation of HIF leads to HIF ubiquitination and degradation under normal oxygen conditions. This is performed by two dioxygenases that are able to hydroxylate HIF $\alpha$ protein. The first is proline-targeting prolyl hydroxylase domain (PHD)-containing enzymes (1, 2 and 3), which are responsible for proline 564 hydroxylation. Proline hydroxylation helps (phi) to recognize multimedia ubiquitin ligase of HIF $\alpha$ [1] [8] [9]. PVHL, besides elongin B (TCEB2), elongin C (TCEB1), cullin 2 (CUL2) and ringbox1 (RBX1), is concerned with the ubiquitination of HIF $\alpha$ subunits that target the 


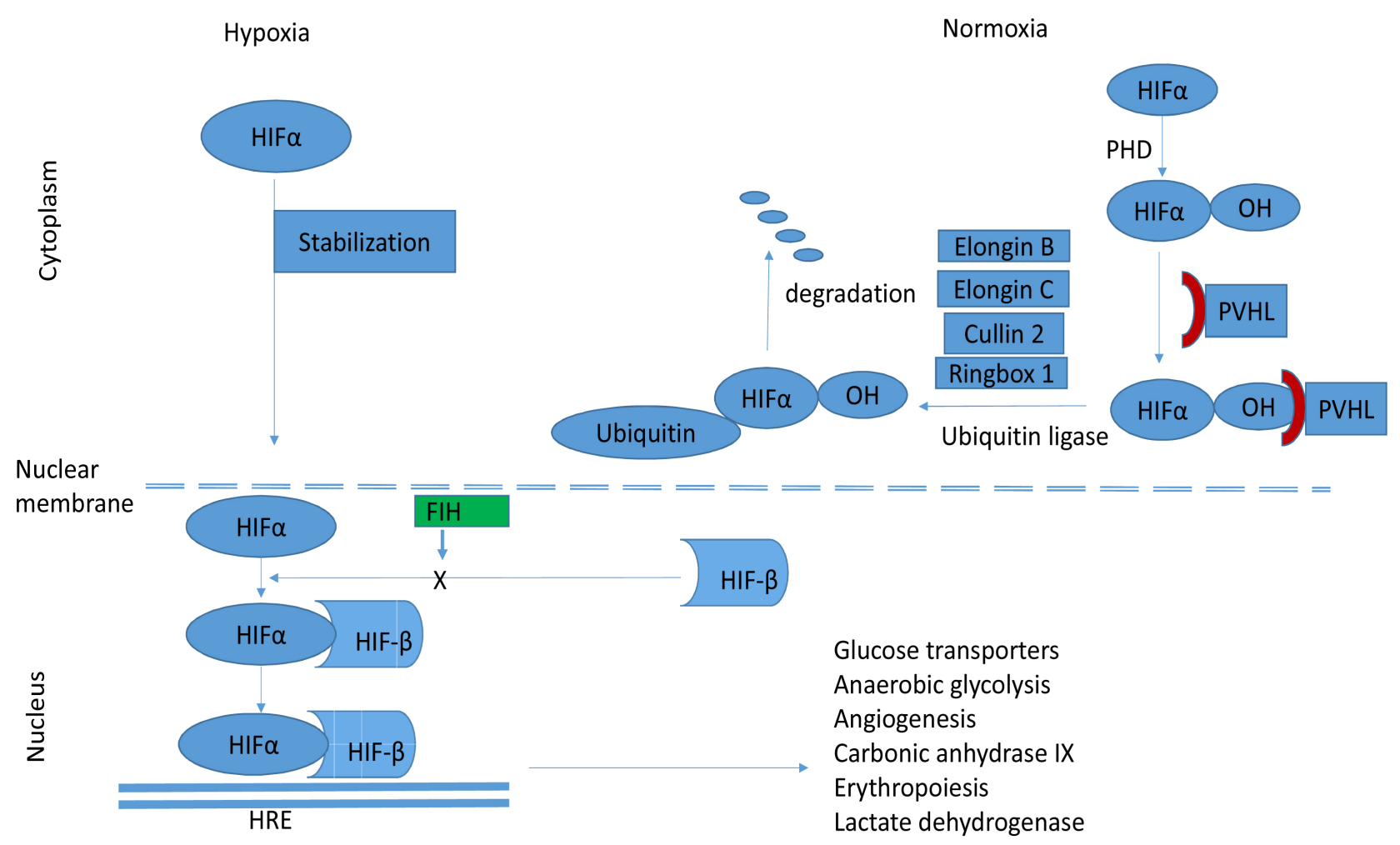

Figure 1. HIF-1 $\alpha$ mode of action under hypoxia condition and degradation under normoxia conditions.

proteome for proteasomal degradation [10]. The second is asparagine-targeting factor inhibiting HIF (FIH) enzyme which is $\mathrm{O}_{2}$ dependent asparaginyl hydroxylase [11]. FIH enzyme inhibits HIF $\alpha$ binding to CREB-binding protein (CBP/p300) which suppresses the trans-activated target genes without affection HIF $\alpha$ structural stability [12]. PHDs and FIH hydroxylation function is suppressed in case of hypoxia, in result HIF $\alpha$ will be accumulated after its stabilization and protection against ubiquitination by pVHL [8] [9] (Figure 1).

\subsection{Role of Carbonic Anhydrase in Cancer Cell pH Control and Its Relationship with Hypoxia}

CA-IX is a glycoprotein (transmembranous) that motivates the reversible hydration of $\mathrm{CO}_{2}$ to $\mathrm{H}_{2} \mathrm{CO}_{3}$ during glycolysis. Also it is present in high concentrations in many cancer cell types and has predictive value of hypoxia in many neoplasms, which have bad prognosis [13]. Intracellular carbonic anhydrase inhibitors isoforms were found to be present in cancer types in high concentrations like colorectal HCT116, Bladder RT112 and colorectal HT29, moderate concentrations in fibrosarcoma HT1080. Malignant neoplasms of low levels of carbonic anhydrase inhibitors are aggressive forms [14].

CA-IX is important for cancer cell signaling, tumor formation, acidification and metastasis, so their inhibition was a target of studies in malignant neoplasms treatment. CA-IX inhibitor showed hoping results in reduction malignancy progression in vitro and in vivo [15]. Sulfonamide based compounds are the most 
successful CA IX inhibitors.

During hypoxia, malignant cells are directed towards metabolic shift of rapid aerobic glycolysis to yield lactic acid even in the presence of oxygen, which is known as the "Warburg Effect" [16]. Export lactic acid and free protons from malignant cells will lower $\mathrm{pHe}$ ( $\mathrm{pH}$ extracellular) to $(6.5$ - 7.1) with mild decrease in $\mathrm{pHi}$ (pH intracellular) to be 7.2 or more [17]. Fast shift of protons transport in and out the cell membrane will equilibrate the metabolic state of the malignant cell in case of any changes [18].

Low pHe will create suitable environment for metastasis and cancer progression [19] by enhancing extracellular matrix (ECM) reorganizational proteasese like matrix metalloproteinases (MMP) and cathepsin [20]. pHi 7.2 or more will predisposed to de novo actin filament formation by activation actin binding proteins such as cofillin, villin, profilin, twinfilin, and talin that preserve tumor cell survival [21] [22] [23] Also conversion of glucose to lactic acid will produce $\mathrm{CO}_{2}$, which is hydrated to carbonic acid $\mathrm{H}_{2} \mathrm{CO}_{3}$, then dissociated to $\mathrm{HCO}_{3}^{-}$and $\mathrm{H}^{+}$(the source of respiratory acidification) [24]. That previous reaction is the function of carbonic anhydrase IX. $\mathrm{HCO}_{3}^{-}$(bicarbonate) and $\mathrm{H}^{+}$(protons) are carried by bicarbonate transporter proteins to blood or tumor cell, in that way the control of $\mathrm{pH}$ in cancer cells is done. Also intracellular tail of CA-IX activates many cancer signaling cascades including HIF $\alpha$. This is performed through the reaction of its phosphorylated tyrosine residue with the regulatory subunit of phosphoinositol 3 kinase (PI3K) that has a role in HIF activation [25].

Acidosis induces resistance to chemo-, radio- and immune-therapies [26]. Also it stimulates angiogenesis, invasion, and metastasis. It is associated with aneuploidy, increased mutation rate, survival and cell migration [27] [28]. Carbonic anhydrase IX has special mechanisms for malignancy progression like acting as an adhesion molecule during cell attachment in solid tumors [29]. It also stimulates angiogenesis by endothelial cells migration [30]. CA-IX induced acidosis releases cells in the form of clusters from the primary tumor into the circulation freely without adhesions in between to augment metastasis [31].

\subsection{Post-Translation Modifications of HIF-1 $\alpha$ Molecule (Figure 2)}

1) Serine 247 phosphorylation: This is performed by casein kinase-1. The phosphorylation of serine 247 will inhibit HIF- $1 \alpha$ action by inhibition its binding to HIF-1 $\beta$ (ARNT) [32].

2) SUMO-1 (small ubiquitin-related modifier) modification at Lys (391, 477, 532, 538 and 547) residues: This stabilizes HIF-1 alpha and enhances its transcriptional activity. (VHL)-E3 ubiquitin ligase binds the target protein and the E2 catalyzes ubiquitin transfer to lysine residues K532, K538 and K547. Only one of these lysine residues need to be intact for full ubiquitination to occur. So, the desumoylated HIF molecule is susceptible to degradation [33].

3) Proline 564 hydroxylation: Hydroxylation of Pro564 is a mechanism of protein recognition by the VHLE3 complex toward ubiquitination [8] [9]. 


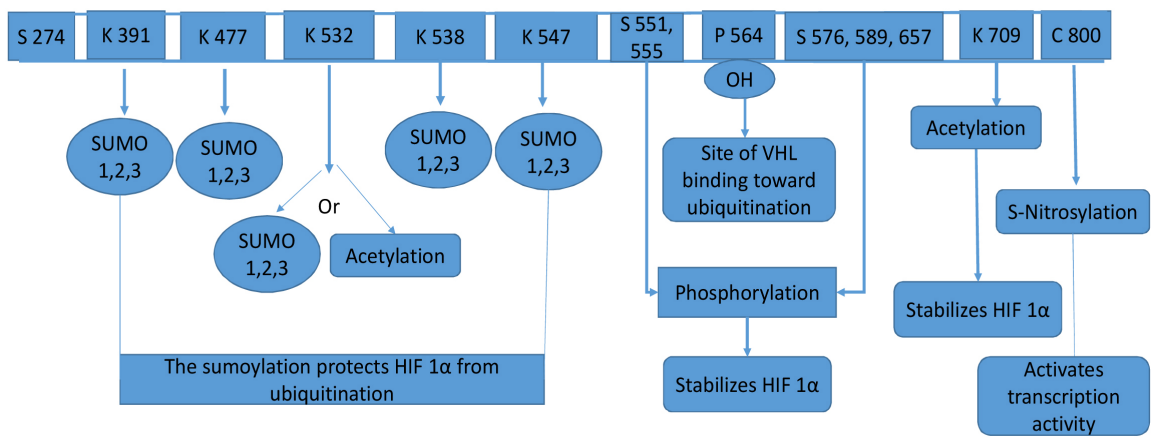

Figure 2. The post-translation modifications of HIF-1 $\alpha$ molecule.

4) lysine 709, 532 acetylation: This protects the HIF- $1 \alpha$ from ubiquitination, hence protein stabilization [34].

5) Serine 551, 555, 576, 589, and 657 phosphorylation by PIK3 (polo-like kinase 3): These phosphorylation processes stabilize the HIF molecule [32].

6) S-nitrosylation of cysteine 800: HIF- $1 \alpha$ was characterized as a potential target for S-nitrosylation. Cys-800 of HIF-1 $\alpha$ protein has a reactive SH-group, which is critical for recruitment of p300 coactivator that is necessary for transcriptional activity of HIF 1 complex when it is translocated to the nucleus [7].

\section{Use of HIF as a Drug Delivery Molecule}

In the malignant cell there is a cycle started from pVHL silencing, inhibition of the hydroxylase activity (PHDs) and FIH, lead to accumulation of HIF- $1 \alpha$, then induction of hypoxic environment. These conditions activate the carbonic anhydrase IX and other enzymes that induce Warburg effect, which results in more acids production from excessive glycolysis. In a result, there will be lowering $\mathrm{pH}$ intracellular and extracellular $(\mathrm{pHe}<\mathrm{pHi})$. This leads to more accumulation and production HIF- $1 \alpha$ that increases malignancy progression and the cycle is repeated.

So, breaking of this cycle is our aim. This can be achieved through two stages: 1) reversal of the acidic environment by carbonic anhydrase IX inhibitor, and 2) damaging malignant cell (that secrete HIF- $1 \alpha$ and CA-IX) DNA genome by platinum containing cytotoxic drug e.g. cisplatin in its glycosylated form. Carbonic anhydrase inhibitor and glycosylated cisplatin will be linked on modified synthetized HIF- $1 \alpha$. Synthetized HIF- $1 \alpha$ from microbial culture media will be modified by adding certain enzymes that promote and inhibit post-translational modifications within the protein. Also those modifications will enable us to attach some therapeutic agents by the way that does not change its 3rd structure. So, the modified HIF- $1 \alpha$ molecule will be used as a drug delivery molecule in ineffective and easily ubiquitinated structure.

Use of modified HIF- $1 \alpha$ as a drug carrier molecule may be shocking, but the affinity of modified HIF- $1 \alpha$ to hypoxic malignant cells expressing CA IX is fairly good. By that way, the uptake of HIF-1 alpha will be easier after CA inhibitor linkage to CA IX expressing malignant cells that secrete HIF-1 alpha. Pep- 
tide-CA inhibitor can enter malignant hypoxic cells by the way of endocytosis [35].

On just entry the cell, carbonic anhydrase inhibitors will improve the cellular $\mathrm{pH}$ that makes the environment unsuitable for HIF-1 $\alpha$ (that is formed by the malignant cells) functioning or it may be ubiquitinated, in a result, it will be accumulated within the cytoplasm not translocated to the nucleus. So, the raise in target genes transcription will be arrested. On the other hand, once the synthetized HIF-1 alpha is degraded the glycosylated cisplatin will be released intracellular. Glycosylated cisplatin is converted to its active form by reducing enzymes e.g. glutathione and ascorbic acid [36], then forming platinum DNA-adducts. The end result is damaging malignant cell DNA, which is the factory of HIF-1 $\alpha$ and CA-IX enzyme specifically.

\section{Materials and Methods}

\section{Three Stages Will Be Needed to Use HIF-1 $\alpha$ as a Drug Delivery Molecule}

\section{1) Microbial production of modified HIF-1 alpha:}

HIF- $1 \alpha$ is produced under aerobic (normoxic) conditions (normoxic conditions are favorable for proline 564 hydroxylation and preserving serine residues without modifications) from $E$. coli strain $\mathrm{K} 12$, which contains flavohemoglobin [37]. Flavohemoglobin is involved in NO detoxification in aerobic process for denitrosylation [38]. Denitrosylation of cysteine 800 is important to be attachment site to CA-IX inhibitor such as functionalized heterocyclic primary sulfonamide with NO moiety. SIR 2 protein is an enzyme which will be injected in the form of liposomal packaging into the culture cells. Its role is to deacetylate lysine 709 mainly that will make it of increased binding affinity for prolyl hydroxylase 2 and increased HIF- $1 \alpha$ hydroxylation and ubiquitination later on when it is used as a therapeutic molecule by VHLp [34]. Also SENP2 protease (desumoylating enzyme) that catalyze two essential functions in the SUMO pathway will be used also in the form of liposomal packaging (liposomes are used as an efficient method to entrap enzymes and transport them into the cells. Unilamellar liposomes (that contain enzymes) fuse with the cell membrane of culture cells and enzymes are introduced into the cytosol, while multilamellar liposome are gradually degraded in the cytoplasm or fused with membrane bound organelles e.g. the nucleus or lysosomes. It is dependable method for in vitro efficient enzymatic biochemical reactions [39]. The first function of SENP2 is the hydrolysis of an alpha linked peptide bond at the C-terminal end of the small ubiquitin like modifier (SUMO) peptidases, SUMO1, SUMO2 and SUMO3 leading to the mature form of the proteins. The second one is the deconjugation of SUMO1, SUMO2 and SUMO 3 from targeted proteins by cleaving an epsilon-linked peptide bond between the C-terminal glycine of the mature SUMO and lysine epsilon-amino group of the target protein (HIF-1 $\alpha$ ) [40]. Hence, desumoylation will preserve glycyl lysine residues available for HIF- $1 \alpha$ ubiquitina- 
tion and deactivation. At the end of this stage, the modified HIF- $1 \alpha$ contains desumoylated lysine residues 391, 477, 532, 538, 547, hydroxylated proline 564, deacetylated lysine 709 and denitrosylated cysteine 800. Also serine residues 551, $555,576,589,657$ are preserved.

2) Serine residues O-glycosylation and binding with glycosylated cisplatin: O-Glycosylation of serine 247, 551, 555, 576, 589 and 657 residues of the purified HIF- $1 \alpha$ by 6 glycosylated cisplatin molecules is performed by a solid phase glycosyltransferase assay. Purified HIF-1 $\alpha$ (carbohydrate acceptor) coupled covalently to polyacrylamide are coated onto well plastic plate. The glycosyltransferase reaction is performed with recombinant enzymes and glycosylated cisplatin at $37^{\circ} \mathrm{C}$, followed by washing and addition of scintillation counting fluid [41]. In that stage, we preferred in vitro O-glycosylation to avoid change HIF-1 $\alpha$ 3D-structure; especially O-glycosylation introduces novel bonding interactions to the protein and preserves its integrity [42]. Also glycosylation preserves protein folding by destabilization of its unfolded condition in noticeable manner than stabilization the folded structure [43].

Choosing glycosylated cisplatin is done because it is a prodrug in inactive form. It will be more efficient than cisplatin as it will resist malignant defense mechanism and will reduce the possible side effects. Other advantages of glycosylated cisplatin are improved bioavailability. So it is easier to enter malignant cells before reduction to platinum (II) forming DNA-platinum adducts damaging malignant DNA nucleotide [36].

3) Binding of HIF-1 $\alpha$-glycosylated cisplatin complex with CA-IX inhibitor:

HIF-1 $\alpha$-glycosylated cisplatin is S-nitrosylated in vitro with functionalized heterocyclic primary sulfonamide with NO moiety (2-methoxy-4-(nitroxy)butoxy)-3oxoprop-1-en-1-yl)benzyl4-sulfamoylbenzoate), which acts as nitric oxide donor [44]. Presence of nitric oxide donor is essential for S-nitrosylation by S100A9 [45]. This in-vitro S-nitrosylation of HIF-1 alpha doesn't change its 3D-structure and it is a very important step because HIF-1 alpha cysteine 800 , if not blocked by carbonic anhydrase inhibitor or any other compounds, it can be S-nitrosylated inside the malignant cell by histone deacetylases or by other different mechanisms e.g. GADPH-mediated trans-nitrosylation enzymes, hence activated to its carcinogenic form. Linking CA-IX inhibitor will direct the synthetized HIF-1 $\alpha$ with glycosylated cisplatin to enter malignant cells that express CA-IX, which is commoner and regarded as a marker for HIF-1 $\alpha$ (CA-IX synthesis is a result from HIF-1 $\alpha$ transcriptional activity [2].

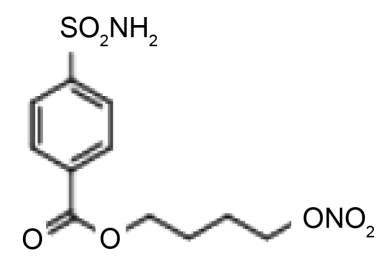

Sulfonamide Carbonic Anhydrase IX inhibitor, with NO moiety:

2-methoxy-4-(3-(4-(nitroxy)butoxy)-3-oxoprop-1-en-1-yl)benzyl4-sulfamoylbenzoate. 
In this hypothesis, sulfonamide CA IX inhibitor and cisplatin is linked to HIF-1 $\alpha$ (Figure 3) (that has familial structure to hypoxic malignant cells) (Figure 4(a)), so that this inhibitor is directed specifically towards malignant hypoxic cell membranes exerting their $\mathrm{pH}$ modulating effect and acidity reversal action, then selectively induces CA-IX-related endocytosis of HIF- $1 \alpha$ alpha-glycosylated cisplatin intracellular. Then synthetized HIF- $1 \alpha$ will face unsuitable intracellular $\mathrm{pH}$, so it will be ubiquitinated (Figure 4(b)) especially after the previously modified post-translational modifications have been done (Figure 3). The final result is release of 6 glycosylated cisplatin platinum-IV molecules (prodrug) after HIF 1 alpha ubiquitination intracellular that will be reduced to platinum II (the active form) by the effect of ascorbic acid and gluthathione that are intensively present in malignant cells [36] making DNA adducts and destroying malignant cell genome (Figure 4(c)).

\section{Conclusion}

Expected scenario when HIF-1 $\alpha$-CA-IX Inhibitor-glycosylated cisplatin complex used as a cytotoxic drug in solid tumors e.g. hepatoma and renal cell carcinoma (hypoxic or pseudo-hypoxic tumor), it will be transferred easily intracellular (inside malignant cells only) because HIF- $1 \alpha$ acts as a targeting component towards malignant cells that express CA-IX. HIF-1 $\alpha$ will enter the hypoxic malignant cells by endocytosis. Carbonic anhydrase IX inhibitor will modify intracellular $\mathrm{pH}$ towards the normal range (less acidic and less hypoxic), which will alter the malignant cell environment to be unsuitable for HIF- $1 \alpha$ functioning especially after blocking its Cys 800, which is nitrosylated and blocked by binding to carbonic anhydrase inhibitor. This is in addition to blocking of the serine residues and preventing its phosphorylation when glycosylated with glycosylated cisplatin. By that way HIF- $1 \alpha$ will be inactive and easily degraded, especially after desumoylation and deacetylation of lysine residues, which are the main route for

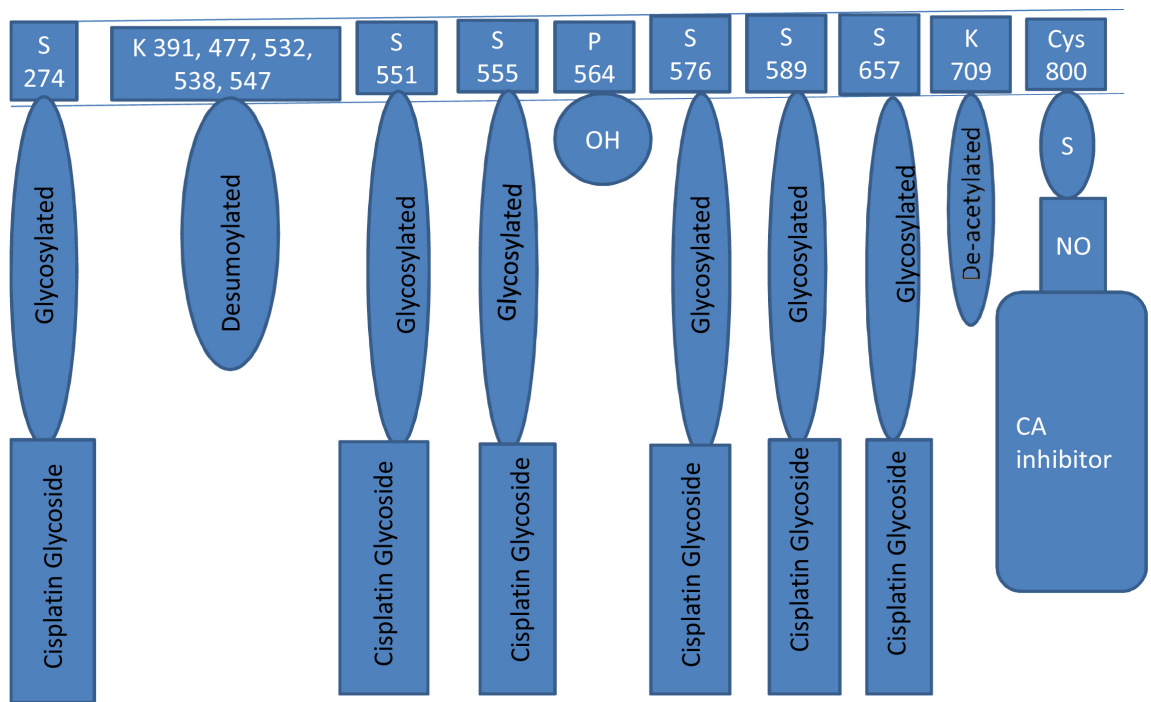

Figure 3. Final form of HIF-1 $\alpha$-CA IX inhibitor-cisplatin glycoside. 


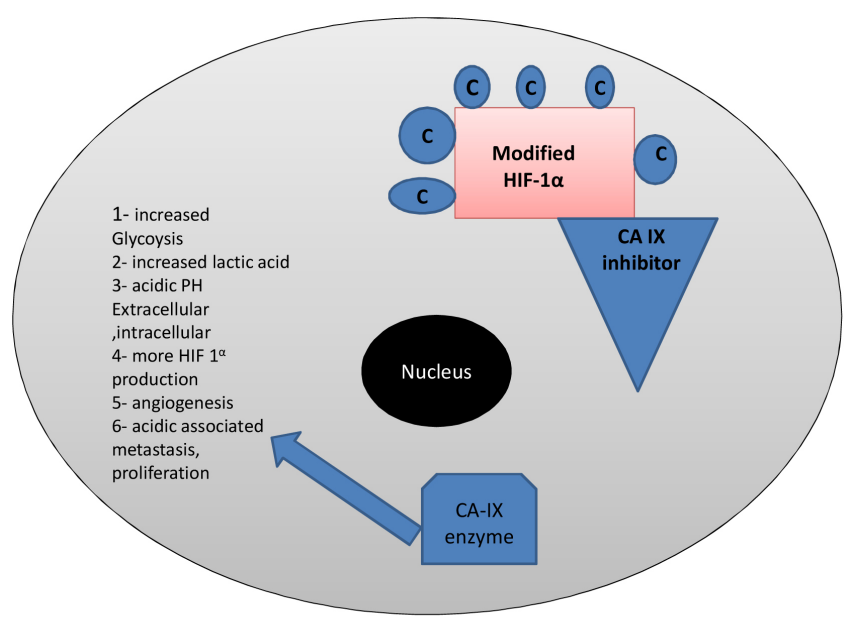

(a)

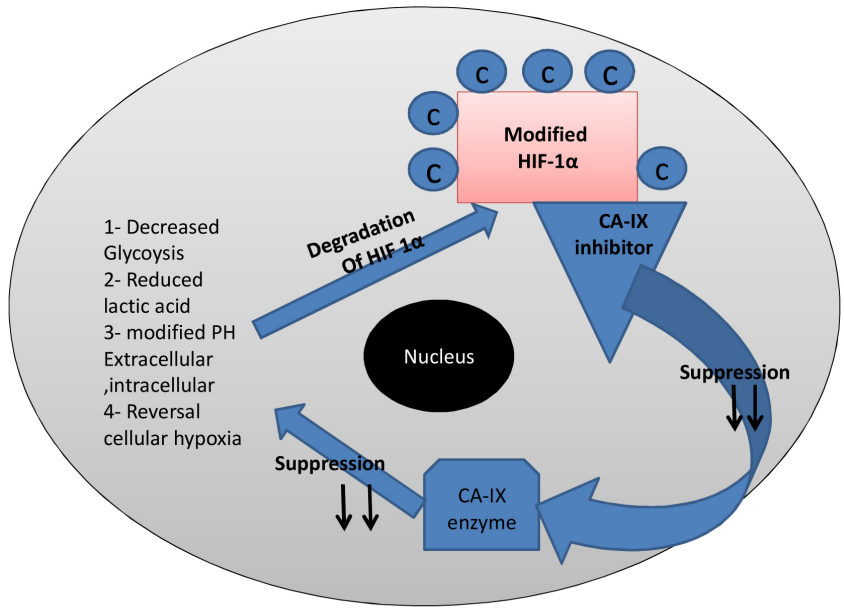

(b)

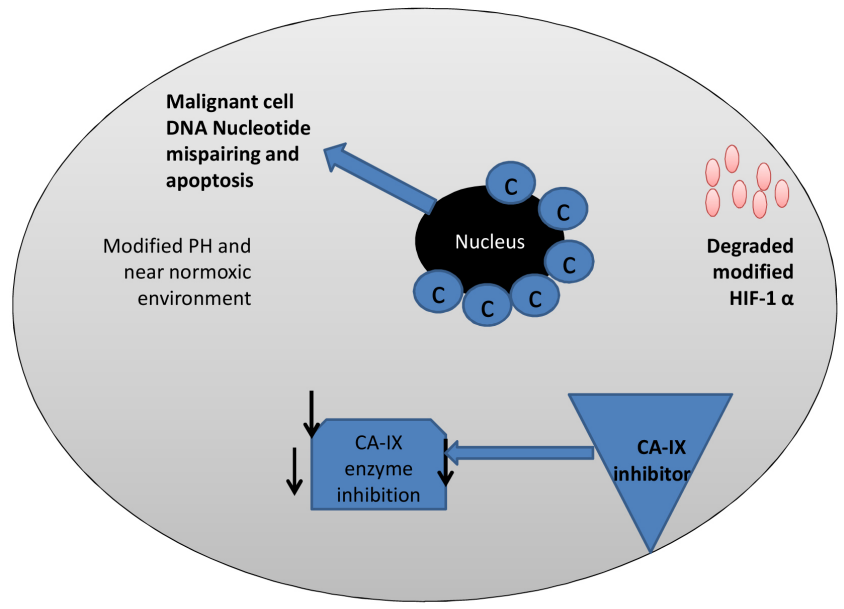

(c)

Figure 4. (a) HIF-1 alpha-cisplatin-carbonic anhydrase-IX inhibitor enters the hypoxic malignant cell that has abundant CA-IX enzyme. (b) CA-IX inhibitor exerts its function by reversal the acidic and the hypoxic environment of malignant cell that predisposes to HIF-1 $\alpha$ ubiquitination. (c) After reversal the acidic PH and the hypoxic environment, modified HIF-1 $\alpha$ is degraded releasing 6 cisplatin molecules freely in the cytoplasm to enter the nucleus and initiate nucleotide mispairing, finally apoptosis. 
its ubiquitination. This can be performed directly through the available lysine residues 532, 538 and 547 by the ubiquitin attachment or indirectly by the hydroxylated proline 564. After HIF-1 $\alpha$ intracellular ubiquitination, the six glycosylated cisplatin molecules will be released and reduced by glutathione and ascorbic acid to its active form, which in turn will form DNA-platinum adducts mispairing malignant cells nucleotide. Cisplatin will have augmentation effect on CA-IX inhibitor in comparison to usage CA-IX inhibitor only because it will destabilize the overproduced genes that are responsible for synthesis glycolysis enzymes, CA IX and angiogenesis proteins. Those genes are responsible for creation the acidic $\mathrm{pH}$ that resists CA-IX inhibitor. That new molecule can be used prior to TACE (Transarterial Chemotherapy) and surgery in large solid tumors like hepatoma and renal cell carcinoma.

\section{Conflicts of Interest}

The authors declare no conflicts of interest regarding the publication of this paper.

\section{References}

[1] Maxwell, P.H., Wiesener, M.S., Chang, G.W., Clifford, S.C., Vaux, E.C., Cockman, M.E., Wykoff, C.C., Pugh, C.W., Maher, E.R. and Ratcliffe, P.J. (1999) The Tumor Suppressor Protein VHL Targets Hypoxia Inducible Factors for Oxygen-Dependent Proteolysis. Nature, 399, 271-275. https://doi.org/10.1038/20459

[2] Kallio, P.J., Pongratz, I., Gradin, K., McGuire, J. and Poellinger, L. (1997) Activation of Hypoxia-Inducible Factor 1 Alpha: Posttranscriptional Regulation and Conformational Change by Recruitment of the Arnt Transcription Factor. Proceedings of the National Academy of Sciences of the United States of America, 94, 5667-5672. https://doi.org/10.1073/pnas.94.11.5667

[3] Arany, Z., Huang, L.E., Eckner, R., Bhattacharya, S., Jiang, C., Goldberg, M.A., Bunn, H.F. and Livingston, D.M. (1996) An Essential Role for P300/CBP in The cellular Response to hypoxia. Proceedings of the National Academy of Sciences of the United States of America, 93, 12969-12973. https://doi.org/10.1073/pnas.93.23.12969

[4] Tian, H., McKnight, S.L. and Russell, D.W. (1997) Endothelial PAS Domain Protein 1 (EPAS1), a Transcription Factor Selectively Expressed in Endothelial Cells. Genes \& Development, 11, 72-82. https://doi.org/10.1101/gad.11.1.72

[5] Schofield, C.J. and Ratcliffe, P.J. (2004) Oxygen Sensing by HIF Hydroxylases. Nat. Rev. Molecular and Cellular Biology, 5, 343-354. https://doi.org/10.1038/nrm1366

[6] Semenza, G.L. (2012) Hypoxia-Inducible Factors: Mediators of Cancer Progression and Targets for Cancer Therapy. Trends in Pharmacological Sciences, 33, 207-214. https://doi.org/10.1016/j.tips.2012.01.005

[7] Sha, Y.G. and Marshall, H.E. (2012) S-Nitrosylation in the Regulation of Gene Transcription. Biochimica et Biophysica Acta, 1820, 701-711. https://doi.org/10.1016/j.bbagen.2011.05.008

[8] Ivan, M., Kondo, K., Yang, H., Kim, W., Valiando, J., Ohh, M., Salic, A., Asara, J.M., Lane, W.S. and Kaelin Jr., W.G. (2001) HIFalpha Targeted for VHL-Mediated Destruction by Proline Hydroxylation: Implications for $\mathrm{O}_{2}$ Sensing. Science, 292, 464-468. https://doi.org/10.1126/science.1059817 
[9] Bruick, R.K. and McKnight, S.L. (2001) A Conserved Family of Prolyl-4-Hydroxylases That Modify HIF. Science, 294, 1337-1340. https://doi.org/10.1126/science.1066373

[10] Kallio, P.J., Wilson, W.J., O’Brien, S., Makino, Y. and Poellinger, L. (1999) Regulation of the Hypoxia-Inducible Transcription Factor 1Alpha by the Ubiquitin-Proteasome Pathway. Journal of Biological Chemistry, 274, 6519-6525. https://doi.org/10.1074/jbc.274.10.6519

[11] David, L., Daniel, J.P., Jeffrey, J.G., Dean, A.W., Murray, L.W. and Richard, K.B. (2002) FIH-1 Is an Asparaginyl Hydroxylase Enzyme That Regulates the Transcriptional Activity of Hypoxia-Inducible Factor. Genes \& Development, 16, 1466-1471. https://doi.org/10.1101/gad.991402

[12] Mahon, P.C., Hirota, K. and Semenza, G.L. (2001) FIH-1: A Novel Protein That Interacts with HIF-1Alpha and VHL to Mediate Repression of HIF-1 Transcriptional Activity. Genes \& Development, 15, 2675-2686. https://doi.org/10.1101/gad.924501

[13] Robertson, N., Potter, C. and Harris, A.L. (2004) Role of Carbonic Anhydrase IX in Human Tumor Cell Growth, Survival and Invasion. Cancer Research, 64, 6160-6165. https://doi.org/10.1158/0008-5472.CAN-03-2224

[14] Alzbeta, H., Nicholas, A., Adrian, L.H., Richard, D.V.-J. and Pawel, S. (2014) Intracellular Carbonic Anhydrase Activity Sensitizes Cancerl Cell pH Signaling to Dynamic Changes in $\mathrm{CO}_{2}$ Partial Pressure. Journal of Biological Chemistry, 289, 2541825430. https://doi.org/10.1074/jbc.M114.547844

[15] Lounnas, N., Rosilio, C., Nebout, M., Mary, D., Griessinger, E., Neffati, Z., Chiche, J., Spits, H., Hagenbeek, T.J., Asnafi, V., et al. (2013) Pharmacological Inhibition of Carbonic Anhydrase XII Interferes with Cell Proliferation and Induces Cell Apoptosis in T-Cell Lymphomas. Cancer Letter, 333, 76-88.

https://doi.org/10.1016/j.canlet.2013.01.020

[16] Brown, J.M. (2007) Tumor Hypoxia in Cancer Therapy. Methods in Enzymology, 435, 297-321. https://doi.org/10.1016/S0076-6879(07)35015-5

[17] Balkwill, F.R., Capasso, M. and Hagemann, T. (2012) The Tumor Microenvironment at a Glance. Journal of Cell Science, 125, 5591-5596. https://doi.org/10.1242/jcs.116392

[18] Menard, L., Maughan, D. and Vigoreaux, J. (2014) The Structural and Functional Coordination of Glycolytic Enzymes in Muscle: Evidence of a Metabolon? Biology, 3, 623-644. https://doi.org/10.3390/biology3030623

[19] Stock, C. and Schwab, A. (2009) Protons Make Tumor Cells Move Like Clockwork. Pflügers Archiv. European Journal of Physiology, 458, 981-992.

https://doi.org/10.1007/s00424-009-0677-8

[20] Bourguignon, L.Y.W., Singleton, P.A., Diedrich, F., Stern, R. and Gilad, E. (2004) CD44 Interaction with $\mathrm{Na}^{+}-\mathrm{H}^{+}$Exchanger (NHE1) Creates Acidic Microenvironments Leading to Hyaluronidase-2 and Cathepsin B Activation and Breast Tumor Cell Invasion. Journal of Biological Chemistry, 279, 26991-27007. https://doi.org/10.1074/jbc.M311838200

[21] Moseley, J.B., Okada, K., Balcer, H.I., Kovar, D.R., Pollard, T.D. and Goode, B.L. (2006) Twinfilin Is an Actin-Filament-Severing Protein and Promotes Rapid Turnover of Actin Structures in Vivo. Journal of Cell Science, 119, 1547-1557. https://doi.org/10.1242/jcs.02860

[22] McLachlan, G.D., Cahill, S.M., Girvin, M.E. and Almo, S.C. (2007) Acid-Induced Equilibrium Folding Intermediate of Human Platelet Profilin. Biochemistry, 46, 69316943. https://doi.org/10.1021/bi0602359

[23] Srivastava, J., Barreiro, G., Groscurth, S., Gingras, A.R., Goult, B.T., Critchley, D.R., 
Kelly, M.J.S., Jacobson, M.P. and Barber, D.L. (2008) Structural Model and Functional Significance of $\mathrm{pH}$-Dependent Talin-Actin Binding for Focal Adhesion Remodeling. Proceedings of the National Academy of Sciences of the United States of America, 105, 14436-14441. https://doi.org/10.1073/pnas.0805163105

[24] Mookerjee, S.A. and Brand, M.D. (2015) Measurement and Analysis of Extracellular Acid Production to Determine Glycolytic Rate. Journal of Visualized Experiments, 12, e53464. https://doi.org/10.3791/53464

[25] Vincenzo, A., Mika, H., Anna, D.F., Claudiu, T.S., Peiwen, P., Seppo, P., Andrea, S., Jaromir, P., Silvia, P., Carlo, P., Andrea, S., Simona, M.M. and De Simone, G. (2009) Crystal Structure of the Catalytic Domain of the Tumor-Associated Human Carbonic Anhydrase IX. Proceedings of the National Academy of Sciences of the United States of America, 106, 16233-16238. https://doi.org/10.1073/pnas.0908301106

[26] Lardner, A. (2001) The effects of extracellular $\mathrm{pH}$ on immune function. Journal of Leukocyte Biology, 69, 522-530.

[27] Wojtkowiak, J.W., Verduzco, D., Schramm, K.J. and Gillies, R.J. (2011) Drug Resistance and Cellular Adaptation to Tumor Acidic $\mathrm{pH}$ Microenvironment. Molecular Pharmacology, 8, 2032-2038. https://doi.org/10.1021/mp200292c

[28] Corbet, C. and Feron, O. (2017) Tumour Acidosis: From the Passenger to the Driver's Seat. Nature Reviews Cancer, 17, 577-593. https://doi.org/10.1038/nrc.2017.77

[29] Csaderova, L., Debreova, M., Radvak, P., Stano, M., Vrestiakova, M., Kopacek, J., et al. (2013) The Effect of Carbonic Anhydrase IX on Focal Contacts during Cell Spreading and Migration. Frontiers in Physiology, 4, 271.

https://doi.org/10.3389/fphys.2013.00271

[30] Horie, K., Kawakami, K., Fujita, Y., Sugaya, M., Kameyama, K., Mizutani, K., Deguchi, T. and Ito, M. (2017) Exosomes Expressing Carbonic Anhydrase 9 Promote Angiogenesis. Biochemical and Biophysical Research Communications, 492, 356-361. https://doi.org/10.1016/j.bbrc.2017.08.107

[31] Gkountela, S., Castro-Giner, F., Szczerba, B.M., Vetter, M., Landin, J., Scherrer, R., Krol, I., Scheidmann, M.C., Beisel, C., Stirnimann, C.U., Kurzeder, C., Heinzelmann-Schwarz, V., Rochlitz, C., Weber, W.P. and Aceto, N. (2019) Circulating Tumor Cell Clustering Shapes DNA Methylation to Enable Metastasis Seeding. Cell, 176, 98-112.E14. https://doi.org/10.1016/j.cell.2018.11.046

[32] Xu, D.Z., Yao, Y.X., Lu, L., Costa, M. and Dai, W. (2010) PIK3 Functions as an Essential Component of the Hypoxia Regulatory Pathway by Direct Phosphorylation of HIF-1Alpha. Journal of Biological Chemistry, 285, 38944-38950. https://doi.org/10.1074/jbc.M110.160325

[33] Bae, S.-H., Jeong, J.-W., Park, J.A., Kim, S.-H., Bae, M.-K., Choi, S.-J. and Kim, K.-W. (2004) Sumoylation Increases HIF-1 Alpha Stability and Its Transcriptional Activity. Biochemical and Biophysical Research Communications, 324, 394-400. https://doi.org/10.1016/j.bbrc.2004.09.068

[34] Seo, K.-S., Park, J.-H., Heo, J.-Y., Jing, K., Han, J., Min, K.-N., Kim, C., Koh, G.Y., Lim, K., Kang, G.-Y., Lee, J.U., Yim, Y.-H., Shong, M., Kwak, T.-H. and Kweon, G.R. (2014) SIRT2 Regulates Tumour Hypoxia Response by Promoting HIF-1 $\alpha$ Hydroxylation. Oncogene, 34, 1354-1362. https://doi.org/10.1038/onc.2014.76

[35] Li, J.Y., Shi, K.J., Sabet, Z.F., Fu, W.J., Zhou, H.G., Xu, S.X., Liu, T., You, M., Cao, M.J., Xu, M.Z., Cui, X.J., Hu, B., Liu, Y. and Chen, C.Y. (2019) New Power of Self-Assembling Carbonic Anhydrase Inhibitor: Short Peptide-Constructed Nanofibers Inspire Hypoxic Cancer Therapy. Science Advances, 5, Article ID: eaax0937. https://doi.org/10.1126/sciadv.aax0937 
[36] Ma, J., Zhang, J.B., Wang, X. and Wang, P. (2016) The Glycosylated Platinum(iv) Prodrugs Demonstrated Significant Therapeutic Efficacy in Cancer Cells and Minimized Side-Effects. Dalton Transactions, 45, 11830-11838. https://doi.org/10.1039/C6DT02207C

[37] Yu, R., Li, X., Zhou, X., et al. (2011) Expression, Purification, and Characterization of Recombinant Human Hypoxia Inducible Factor $1 \alpha$ in E. coli. World Journal of Microbiology and Biotechnology, 27, 453-458.

https://doi.org/10.1007/s11274-010-0453-0

[38] Alexander, D.F., Judith, F., Christian, J.T. and Bollinger, P.T.K. (2002) Bacterial Hemoglobins and falvohemoglobins for Alleviation of Nitrosative Stress in Escherichia coli. Applied and Environmental Microbiology, 68, 4835-4840. https://doi.org/10.1128/AEM.68.10.4835-4840.2002

[39] Morris, F. and Gerald, W. (1978) The Introduction of Enzymes into the Cells by Means of Liposomes. Journal of Lipid Research, 19, 289-303.

https://doi.org/10.1016/S0022-2275(20)41300-8

[40] Jung, H.K. and Sung, H.B. (2008) Emerging Roles of Desumoylating Enzymes. Biochim. Biochimica et Biophysica Acta, 1792, 155-162.

https://doi.org/10.1016/j.bbadis.2008.12.008

[41] Donovan, R.S., Datti, A., Beak, M.G., Wu, Q., Sas, I.J., Korczak, B., Berger, E.G., Roy, R. and Dennis, J.W. (1999) A Solid Phase Glycosyltransferase Assay for HighThroughput Screening in Drug Discovery Research. Glycoconjugate Journal, 16, 607-615. https://doi.org/10.1023/A:1007024916491

[42] Patrick, K.C., Guan, X.Y., Chen, C., Ruan, Y., Wang, X.F., Tran, A.H., Koelsch, T.N., Cui, Q., Feng, Y.G. and Tan, Z.P. (2017) Structural Insight into the Stabilizing Effect of O-Glycosylation. Biochemistry, 56, 2897-2906.

https://doi.org/10.1021/acs.biochem.7b00195

[43] Dalit, S.-B. and Yaakov, L. (2008) Effect of Glycosylation on Protein Folding: A Close Look at Thermodynamic Stabilization. Proceedings of the National Academy of Sciences of the United States of America, 105, 8256-8261. https://doi.org/10.1073/pnas.0801340105

[44] Carradori, S., Mollica, A., De Monte, C., Ganese, A. and Supuran, C.T. (2015) Nitric Oxide Donors and Selective Carbonic Anhydrase Inhibitors: A Dual Pharmacological Approach for the Treatment of Glaucoma, Cancer and Osteoporosis. Molecules, 20, 5667-5679. https://doi.org/10.3390/molecules20045667

[45] Nancy, R.G. (2014) Knowing Where to S-Nitrosylate. Science Signaling, 7, ec314. https://doi.org/10.1126/scisignal.aaa2540 


\section{List of Abbreviations}

ARNT: aryl-hydrocarbon-receptor nuclear translocator

CA 1X: Carbonic anhydrase IX

CBP: cAMP-regulated-enhancer-binding protein

CREB: cAMP response element binding protein

FIH: asparagine-targeting factor inhibiting HIF

GADPH: glyceraldhyde 3 phosphate dehydrogenase

GLUT: Glucose transporter

HIF-1 $\alpha$ : hypoxia inducible factor 1 alpha

HRE: Hypoxia response elements

P300: protein homologous to CBP

PAS: Per-ARNT-Sim domain protein

PHD: prolyl hydroxylase domain

pVHL: Proline hydroxylation VHL

RCGTG: nucleotide DNA sequence

VEGF: Vascular endothelial growth factor

VHL: von hipple landau 